Clarke, P. H. \& Tracey, M. V. (1956). J. gen. Microbiol. 14, 188-196

\title{
The Occurrence of Chitinase in some Bacteria
}

\author{
By PATRICIA H. CLARKE \\ National Collection of Type Cultures, London, N.W. 9* \\ AND M. V. TRACEY \\ Biochemistry Department, Rothamsted Experimental Station, \\ Harpenden, Hertfordshire
}

SUMMARY: A method for the detection of small quantities of chitinase in culture fluids is described and the results of a survey of representative species of the main groups of bacteria presented. Chitinase is produced by some but not all of the soil and water bacteria. Chitinase appears to be a constitutive enzyme in many species of bacteria; its occurrence may prove of diagnostic value.

Chitin decomposition is known to be initiated by a large number of bacterial species isolated from marine deposits or from soil (Campbell \& Williams, 1951; Veldkamp, 1955). During a search for a convenient source of chitinase (Tracey, 1955b) a number of cultures of bacteria of medical provenance as well as soil and plant pathogenic organisms were examined. A surprising number of organisms, including human pathogens, was found to produce chitinase, and it seems possible that this property may be of diagnostic value.

\section{METHODS}

Organisms were grown at Rothamsted on nutrient broth (10 g. peptone; $3 \mathrm{~g}$. Lemco; $1 \mathrm{~g}$. Marmite; $5 \mathrm{~g}$. $\mathrm{NaCl}$; made to $1 \mathrm{l}$. with distilled water; $\mathrm{pH} \mathrm{7.2)} \mathrm{or}$ on nutrient agar. Organisms grown by P. H. C. working at the National Collection of Type Cultures (NCTC) were grown in nutrient broth (10 g. peptone; $10 \mathrm{~g}$. Lemco; $5 \mathrm{~g}$. $\mathrm{NaCl}$; water to $1 \mathrm{l} ; \mathrm{pH} 7 \cdot 4$ ) with the exception of the clostridia which were grown in meat broth containing particles of meat. Cultures were incubated with toluene overnight before use.

Chitin. The shells of Sepia officinalis were used as a source (they are commercially available as cuttlefish 'bones'; imported usually from Portugal or India where they are gathered in a dry bleached condition from the beaches). After soaking in dilute $\mathrm{HCl}$ each shell disintegrates into one thick chitinous layer (the pro-ostracum) and a large number of chitinous sheets (about $7 \mu$. thick) with irregular surfaces. The yield from the shells is about $3 \%$, and about two-thirds of the dry weight of the sheets is chitin. This material was dispersed in cold conc. $\mathrm{HCl}$ and, after centrifugation or filtration through glass wool, poured into $10 \mathrm{vol}$. of water, with vigorous stirring. The precipitated finely divided chitin was washed and concentrated by decantation and a thick suspension finally dialysed against running distilled water. A suspension containing $100 \mu \mathrm{g}$. chitin $\mathrm{N} / \mathrm{ml}$. was used as the stock substrate and preserved with toluene.

* Present address: Biochemistry Department, University College, London. 
Chitinase. After incubation overnight with toluene cultures were centrifuged and $2 \mathrm{ml}$. of the supernatant mixed with $2 \mathrm{ml}$. of pH 5 acetate buffer $(0 \cdot 2 \mathrm{M})$ and $1 \mathrm{ml}$. of chitin suspension in centrifuge tubes. Controls of the same total volume containing culture fluid without chitin, and with chitin and buffer alone were also prepared. To all tubes a few drops of toluene were added, the tubes stoppered and the contents mixed. After incubation at $37^{\circ}$ for 1,3 and 8 days the tubes were centrifuged and the acetylglucosamine content of the supernatant fluid determined. When the organisms produced indole a determination before incubation with chitinase was made. The presence of acetylglucosamine was detected by a modification of the Morgan \& Elson (1934) method (Tracey, 1955a). In this method a colour is formed by the reaction of $p$-dimethylaminobenzaldehyde (Ehrlich reagent) with the product formed by heating acetylglucosamine in alkaline solution. A colour is also produced in this reaction by acetylgalactosamine and by blood group mucoids (Aminoff, Morgan \& Watkins, 1952) but not by the disaccharide ( $N, N^{\prime}$-diacetylchitobiose) which is the simplest product, other than acetylglucosamine, of the incomplete enzymic hydrolysis of chitin (Reynolds, 1954; Kuhn, Gauhe \& Baer, 1954). Under the conditions used indole gives a very similar colour (indole colour absorbs maximally at $565 \mathrm{~m} \mu$.; acetylglucosamine colour at $580 \mathrm{~m} \mu$.) with about 2.5 times the intensity of that given by acetylglucosamine of equimolar concentration. Thus the appearance of a pink colour after the reaction has been carried out indicates the presence of free acetylglucosamine, indole or possibly breakdown products of chitin other than $N, N^{\prime}$-diacetylchitobiose. In centrifuged fluids from toluene-killed cultures there was no further production of indole on incubation while in the presence of chitinase the production of material which reacted with Ehrlich reagent after alkaline heating was continued for many days. Only in the presence of indole was any colour produced in the controls. Consequently, chitinase may be detected in culture fluids from indole-producing organisms since in its presence there is a steady increase in the colour produced in the presence of chitin but no increase in its absence. It seems probable that the material responsible for increased colour production as a result of incubation with chitin is acetylglucosamine alone, though it is possible that large fragments resulting from the breakdown of chitin may react in a manner similar to the blood group mucoids. Should this be so, colour production is still indicative of chitin breakdown and hence of the presence of chitinase, for this term may apply to a number of enzymes of different properties with different end products of hydrolysis.

In the absence of indole the presence of $0 \cdot 25 \mu \mathrm{g}$. acetylglucosamine- $N$ can be detected in $1 \mathrm{ml}$. of fluid after incubation with chitin corresponding to the breakdown of a total of $18 \mu \mathrm{g}$. chitin $(1 \cdot 25 \mu \mathrm{g}$. chitin- $N)$. In the presence of indole a rather greater breakdown must have occurred for a positive result to be recognized.

Cellulase. Some cellulase determinations were made on a few culture fluids by a viscometric technique, with sodium carboxymethylcellulose as substrate (Tracey, 1950). 
Indole production. Indole production was also detected by the use of oxalic acid papers inserted above cultures growing in Lemco broth at $37^{\circ}$.

Methyl-red test. Carried out by growing cultures in glucose phosphate peptone medium and incubating for 5 days at $30^{\circ}(\%, w / v$ : glucose 0.5 ; peptone $0.5 ; \mathrm{K}_{2} \mathrm{HPO}_{4} 0.5$ ) and by the methods described by Jennens (1954).

Voges-Proskauer test. Carried out on three media: glucose + phosphate + peptone medium; glucose + peptone medium with $\mathrm{NaCl}$ in place of phosphate (Smith, Gordon \& Clark, 1946); and glucose + peptone medium without salt or phosphate (Abd-el-Malek \& Gibson, 1948). Cultures were incubated at $30^{\circ}$ for 5 days and tested for the presence of acetoin by Batty-Smith's (1941) modification of Barritt's (1936) $\alpha$-naphthol method.

\section{RESULTS}

\section{Liberation of enzyme}

About $100 \mathrm{mg}$. wet weight of Klebsiella (Aerobacter) sp. grown on nutrient agar were suspended in water. Three treatments were compared for enzyme liberation. Incubation overnight with 3M-glycine (Maculla \& Cowles, 1948) resulted in the liberation of $\mathbf{1 . 2}$ units of cellulase, freezing and thawing four times resulted in the presence of 25 units in the supernatant fluid and incubation with toluene overnight at $37^{\circ}$ of 49 units.

\section{Effect of conditions of growth}

Six irregular coliform organisms were grown on nutrient broth for 2,4 and 6 days at $37^{\circ}$. Maximum chitinase activity was reached at 2 days for one strain, at 4 days for a second and at 6 days for the remainder. These cultures were all of low chitinase activity. An active organism, Pseudomonas hydrophila (NCTC 7810), was grown in nutrient broth and in similar broth containing $1 \%$ glucose. Chitinase production was decreased by a factor of 3-5 by the addition of glucose. Five to six days of incubation at $37^{\circ}$ without added glucose was adopted as a routine for the growth of cultures.

Table 1. Effect of varied conditions of growth on the production of cellulase and chitinase, by two Klebsiella species

Toluene-killed cultures incubated 3 days with appropriate substrates; carboxymethylcellulose for cellulase, finely divided chitin for chitinase.

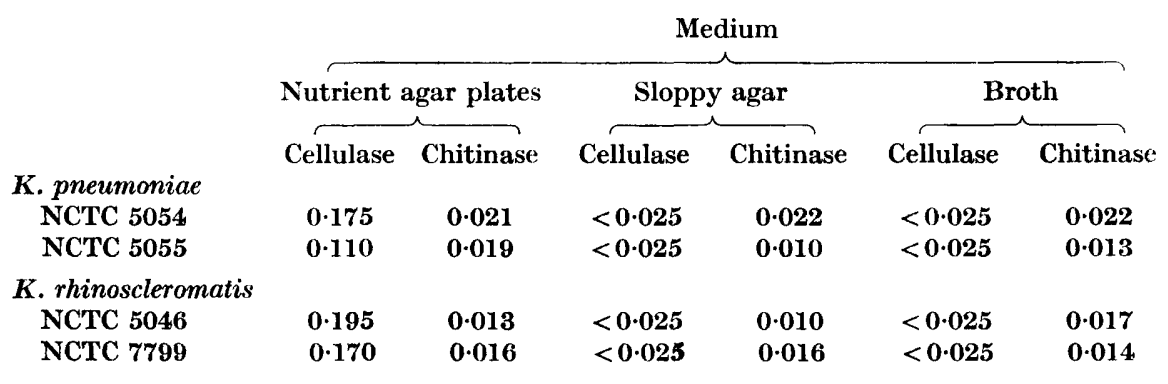

Figures are for total reducing sugar and total acetylglucosamine formed respectively. 
A comparison of enzyme production on liquid and solid media showed that the ratio of cellulase activity to chitinase activity in Klebsiella pneumoniae and $\boldsymbol{K}$. rhinoscleromatis was markedly affected by change of medium. Accordingly, a comparison was made between organisms grown on nutrient broth, on similar broth containing $0.05 \%$ agar (insufficient to solidify it) and on broth containing $1.5 \%$ agar poured into Petri dishes. It is apparent from the results (Table 1 ) that the detection of cellulase production is easier when the organisms are grown on the solid medium, while the ease of detection of chitinase is unaffected. The presence of agar in the liquid medium had no effect on the relative amounts of the enzymes.

No chitin was added to the media used for the growth of the organisms and none was detected in it by chemical analysis. Incubation with a powerful chitinase from Lycoperdon pyriforme (Tracey, 1955a) did not result in the formation of any detectable acetylglucosamine. If any chitin was present its concentration must have been $<6 \mathrm{mg}$./l. No acetylglucosamine was detected in the medium.

\section{Properties of the enzyme}

That the enzyme (or enzymes) concerned in the breakdown of chitin is fairly stable is indicated first by its withstanding incubation with toluene overnight in the absence of substrate and secondly by the fact that acetylglucosamine production from chitin at $37^{\circ}$ normally continues at a fairly steady rate for 10 days or more. Pseudomonas hydrophila extracts were considerably more active at $\mathrm{pH} 5$ than at $\mathrm{pH} 7$. Some of the organisms were tested for the ability to de-acetylate the acetylglucosamine produced. With no organism tested was there any evidence of the production of glucosamine even after prolonged incubation. Since the cultures used were killed it is unlikely that de-acetylation occurred immediately followed by destruction of any glucosamine formed.

It is known that some cellulase preparations are more active in the breakdown of cellulose in the presence of added protein (Whitaker, 1952; Tracey, 1953). This effect has also been found for some fungal chitinases (Tracey, $1955 b$ ). The effect of adding protein to the chitinase assay medium was therefore tried. The addition of a drop of dialysed bovine serum to the contents of the tubes in which chitin was incubated with the extracts materially increased the activity observed. The amount of acetylglucosamine produced during a given interval was increased in the presence of the added protein by a factor varying from 2 to 5 . The variation was probably related to the variation in protein concentration of the extracts tested. This activation by protein enables definite results to be obtained more quickly with weak chitinase producers and was later adopted as a routine, dialysed bovine serum also being added to the control tubes.

\section{Distribution of chitinase}

A survey of representative species of the main groups of bacteria showed that chitinase was produced by some but not all of the soil and water organisms (Table 2). The most active preparations were obtained from species of 
Table. 2. Distribution of chitinase among various bacteria

Organism

Chromobacterium essayanum

C. indicum

C. prodigiosum

C. prodigiosum

C. violaceum

Klebsiella aerogenes

K. aerogenes

K. aerogenes

K. aerogenes

Pseudomonas hydrophila

P. ichthyosmia

$\boldsymbol{P}$. pyocyanea (aeruginosa)

Pseudomonas sp.

Pseudomonas sp.

Clostridium oedematiens type A

C. septicum

C. septicum

C. sporogenes

C. tetani

C. welchii type A

C. welchii (heat resistant)

Vibrio cholerae subgroup I

$V$. cholerae subgroup I

$V$. cholerae subgroup I

V. el Tor

Vibrio sp.

Vibrio sp.

Vibrio sp.

Escherichia coli

E. coli

E. coli

E. coli

E. coli

Erwinea aroideae

E. aroideae

E. carotovora

Ervinea sp.

Erwinea sp.

Erwinea sp.

Proteus mirabilis

P. mirabilis

P. morganii

P. morganii

P. rettgeri

P. rettgeri

Salmonella enteritidis

S. paratyphi-A

$S$. paratyphi-B

S. paratyphi-C

S. typhi

S. typhimurium

S. typhisuis

Shigella boydii

S. dysenteriae

S. dysenteriae

S. dysenteriae
Reference

number

NCTC 4618

2847 *

3804

4612

8683

RES 07

RES 1912*

NCTC 8167

418

$7810^{*}$

8049 *

RES 2650

RES 4002

RES 4036

NCTC 277

284*

285*

534

5410

8246*

8449

6560 *

7252*

8022

4714*

30

4716*

8042

8164

8169

8170

8196

RES

M 16

RES

M

RES

M 13

M 23

NCTC 3156

6789

1709

2814

7477

7478

NCTC 3046

8012

8458

8053

779

3173

5739

8214

6338

8005

8019

Chitinase

production

$+$

$+$

+
+ 
Table 2 (cont.)

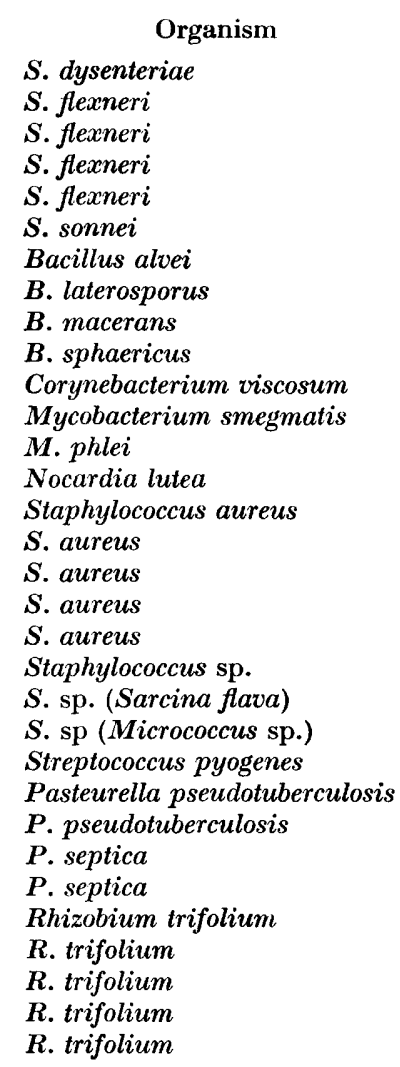

\begin{tabular}{|c|c|c|}
\hline & $\begin{array}{c}\text { Reference } \\
\text { number }\end{array}$ & $\begin{array}{l}\text { Chitinase } \\
\text { production }\end{array}$ \\
\hline & 8379 & - \\
\hline & 2 & - \\
\hline & 7885 & - \\
\hline & 8061 & - \\
\hline & 8192 & - \\
\hline & 7240 & - \\
\hline & 7583 & - \\
\hline & 7579 & - \\
\hline & 7588 & - \\
\hline & 7582 & - \\
\hline & 2416 & - \\
\hline & 525 & - \\
\hline RES & & - \\
\hline RES & & - \\
\hline & 8349 & - \\
\hline & 8353 & - \\
\hline & 8355 & - \\
\hline & 8357 & - \\
\hline & 8363 & - \\
\hline & 952 & - \\
\hline RES & 611 & - \\
\hline RES & T 20 & - \\
\hline & 8328 & - \\
\hline & 1101 & - \\
\hline & 2478 & - \\
\hline & 1287 & - \\
\hline & 4881 & - \\
\hline RES & Coryn & - \\
\hline RES & CIF & - \\
\hline RES & A 11 & - \\
\hline RES & HKC & - \\
\hline RES & A 121111 & - \\
\hline
\end{tabular}

NCTC numbers unless marked otherwise; *=reaction enhanced by added protein; absence of mark from positive organisms means protein effect not tested. RES = cultures from Rothamsted Experimental Station; $\mathbf{M}=$ cultures supplied by Dr J. F. Malcolmson.

Chromobacterium, Pseudomonas and Klebsiella. Two Pseudomonas spp. isolated from soil failed to produce chitinase, and $P$. hydrophila NCTC 7810 appeared to have lost the ability to produce chitinase when retested 2 years later (other organisms retested had retained full activity). Weaker reactions were given by some species of water vibrios and clostridia. Rhizobium trifolium strains were all negative; one Erwinia culture produced chitinase.

Of particular interest were the reactions of the enterobacteria. Klebsiella aerogenes strains produced chitinase, whereas Escherichia coli in common with the salmonellas was negative. Table 3 shows that chitinase production among the coliform organisms was mainly confined to the Klebsiella group. Of the Klebsiella aerogenes I (indole-negative) cultures five were chitinase-positive and one chitinase-negative. Of the $\boldsymbol{K}$. aerogenes II (indole-positive) cultures, five were chitinase-negative and one (NCTC 8848) doubtful. All the strains tested of K.cloacae, K.ozaenae, K.pneumoniae and K.rhinoscleromatis were chitinase producers. Six cultures tested which had been classified as coliform irregular 
were tested; all except NCTC 8866 produced indole and gave positive methyl red and Voges-Proskauer reactions when tested on peptone media. Jennens (1954) showed that in the inorganic medium of Fouad \& Richards (1952) they were methyl-red negative. These six cultures all gave a weak chitinase reaction.

Table 3. Chitinase production among coliform bacteria

Species

Klebsiella aerogenes I

$\boldsymbol{K}$. aerogenes $\mathbf{I}$

K. aerogenes I

K. aerogenes I

K. aerogenes I

$\boldsymbol{K}$. aerogenes $\mathbf{I}$

$K$. aerogenes II

K. aerogenes II

$\boldsymbol{K}$. aerogenes II

$K$, aerogenes II

$K$. aerogenes II

$K$. aerogenes II

K. cloacae

K. cloacae

K. cloacae

K. cloacae

K. ozaenae

K. ozaenae

K. pneumoniae

K. pneumoniae

K. rhinoscleromatis

K. rhinoscleromatis

Escherichia coli I

E. coli I

E. coli II

E. coli II

E. coli II

E. coli mutabile

E. intermedium

E. intermedium

E. intermedium

Irregular coliforms

Irregular coliforms

Irregular coliforms

Irregular coliforms

Irregular coliforms

Irregular coliforms

\begin{tabular}{|c|c|c|c|}
\hline & No. & Chitinase & Indole \\
\hline & 4.18 & + & - \\
\hline & 243 & + & - \\
\hline & 8197 & + & - \\
\hline $\mathbf{M}$ & 4 & - & - \\
\hline $\mathbf{M}$ & 20 & + & - \\
\hline RES & $1912^{*}$ & + & - \\
\hline & 8167 & - & + \\
\hline & 8801 & - & + \\
\hline & 8824 & - & + \\
\hline & 8848 & $+?$ & + \\
\hline & 8874 & - & + \\
\hline RES & 07 & - & + \\
\hline & 5920 & + & - \\
\hline & 6027 & + & - \\
\hline & 8155 & + & - \\
\hline & 8168 & + & - \\
\hline & 5051 & + & - \\
\hline & 5053 & + & - \\
\hline & 5054 & + & - \\
\hline & 5055 & + & - \\
\hline & 5046 & + & - \\
\hline & 7799 & + & - \\
\hline & 8169 & - & + \\
\hline & 8196 & - & + \\
\hline & 8164 & - & - \\
\hline & 8170 & - & - \\
\hline RES & & - & - \\
\hline & 8450 & - & + \\
\hline & 6071 & - & + \\
\hline & 8165 & - & - \\
\hline & 8166 & - & - \\
\hline & 8835 & $+\dagger$ & + \\
\hline & 8844 & $+t$ & + \\
\hline & 8845 & $+\dagger$ & + \\
\hline & 8847 & $+t$ & + \\
\hline & 8851 & +1 & + \\
\hline & 8866 & $+t$ & - \\
\hline
\end{tabular}

NCTC numbers unless marked otherwise; n.t. = not tested; $\dagger=$ reactions weak; ${ }^{0}+$ in peptone media, - in glucose salt medium; * = reaction enhanced by added protein, absence of mark from positive organisms means protein effect not tested. RES =cultures from Rothamsted Experimental Station; $M=$ cultures from Dr J. F. Malcolmson.

\section{Distribution of cellulase}

All strains tested of Klebsiella pneumoniae, $K$. ozaenae and $K$. rhinoscleromatis produced cellulase, as did the only strain of $K$.aerogenes tested (RES 1912). Strains of Escherichia freundii and E. coli mutabile were negative. Five strains of Rhizobium trifolium and single cultures of Erwinea aroideae, 
Nocardia lutea, Mycobacterium smegmatis and $M$. phlei were negative. Among this small group cellulase was present whenever chitinase was found and absent in the organisms that were chitinase negative.

\section{DISCUSSION}

The method described allows the detection of an amount of enzyme breaking down $20 \mu \mathrm{g}$. of precipitated chitin after 10 days at $37^{\circ}$. It may therefore be more sensitive than methods which depend on halo production by colonies grown on agar containing suspended chitin. When the result is positive there seems at present to be little likelihood of its being false. However, it is possible that false negatives may be found. In the present work no evidence of deacetylation of acetylglucosamine during incubation was obtained with any of the cultures tested. The effect of de-acetylation is to produce a false negative, for glucosamine gives no colour with the method used. Should deacetylation occur it may be detected by testing the supernatant fluids for glucosamine as well as acetylglucosamine. This method (which involves heating the solution with an alkaline solution of acetylacetone followed by colour development under rather different conditions with Ehrlich reagent) has the disadvantage that both acetylglucosamine and glucosamine give a positive reaction. On an equimolar basis, however, colour production by glucosamine is six to seven times as great as with acetylglucosamine. Roseman (1954) reported the presence in cell-free extracts of Escherichia coli of an enzyme which deacetylated acetylglucosamine; the optimum $\mathrm{pH}$ value was $8 \cdot 3$, no activity was detectable in pyrophosphate buffer and activity was enhanced when acetylglucosamine was present in the growth medium. It is possible that the absence of acetylglucosamine from the growth medium and incubation at $\mathrm{pH} 5$ would have rendered de-acetylation inappreciable in the experiments reported in the present paper.

The absence (so far as could be determined) of chitin, of glucosamine or acetylglucosamine polymers and of acetylglucosamine from the growth medium would suggest that chitinase is a 'constitutive' enzyme whose presence depends neither on the presence of the substrate nor of its products of hydrolysis in the medium. A similar suggestion for the nature of some bacterial cellulases was advanced by Hammerstrom, Claus, Coghlan \& McBee (1955).

We are grateful to Drs L. M. Crump and B. N. Singh, lately of the Microbiology Department, Rothamsted Experimental Station, and Dr J. F. Malcolmson of the Agricultural Research Council Potato Storage Investigation Team, Sutton Bonnington, Leics., for the gift of cultures.

\section{REFERENCES}

Abd-el-Malek, Y. \& Gibson, T. (1948). Studies in the bacteriology of milk. II. The staphylococci and micrococci of milk. J. Dairy Res. 15, 249.

Aminoff, D., Morgan, W. T. J. \& Watkins, W. M. (1952). Studies in immunochemistry. II. The action of dilute alkali on the $N$-acetylhexosamines and the specific blood-group mucoids. Biochem. J. 51, 379. 
Barritr, M. M. (1936). The intensification of the Voges-Proskauer reaction by the addition of $\alpha$-naphthol. J. Path. Bact. 42, 441.

BatTy-Smith, C. G. (1941). The detection of acetyl-methyl-carbinol in bacterial cultures. A comparative study of the methods of O'Meara and of Barritt. J. Hyg., Camb. 41, 521.

Campbell, L. L. \& Williams, O. B. (1951). A study of chitin-decomposing microorganisms of marine origin. J. gen. Microbiol. 5, 894.

Fouad, M. T. A. \& Richards, T. (1952). The use of glucose inorganic salts media in the classification of the coli-aerogenes bacteria. I. The methyl red and VogesProskauer reactions. Proc. Soc. appl. Bact. 16, 35.

Hammerstrom, R. A., Claus, K. D., Coghlan, J. W. \& McBee, R. H. (1955). The constitutive nature of bacterial cellulase. Arch. Biochem. 56, 123.

Jennens, M. G. (1954). The methyl red test in peptone media. J. gen. Microbiol. $10,21$.

Kuhn, R., Gauhe, A. \& BaEr, H. H. (1954). Einfluss von Substituenten auf die Farbreaktion von $N$-Acetyl-glucosamin mit $p$-Dimethylamino-benzaldehyd. Ber. dtsch. chem. Ges. 87, 1138.

Maculla, E. S. \& Cowles, P. B. (1948). The use of glycine in the disruption of bacterial cells. Science, 107, 376.

MoraAn, W. T. J. \& Erson, L. A. (1934). A colorimetric method for the determination of $N$-acetylglucosamine and $N$-acetylchondrosamine. Biochem. J. 28, 988.

Reynolds, D. M. (1954). Exocellular chitinase from a Streptomyces sp. J. gen. Microbiol. 11, 150.

Roseman, S. (1954). Hydrolysis of $N$-acetyl-D-glucosamine by extracts of Escherichia coli. Fed. Proc. 13, 283.

Smith, N. R., Gordon, R. E. \& Clark, F. E. (1946). Aerobic spore forming bacteria. Misc. Publ. U.S. Dep. Agric. no. 559.

Tracey, M. V. (1950). Cellulase from leaves and roots of tobacco. Biochem. J. 47,431 .

Tracey, M. V. (1953). Cellulase. Symp. biochem. Soc. 11, 49.

Tracey, M. V. (1955a). Chitin: 'Modern Methods of Plant Analysis', ed. K. Paech \& M. V. Tracey, 2, 264. Heidelberg: Springer-Verlag.

Tracey, M. V. $(1955 b)$. Chitinase in some basidiomycetes. Biochem. J. 61, 579.

VeldKamp, H. (1955). A study of the aerobic decomposition of chitin by microorganisms. Meded. LandbHoogesch., Wageningen, 55, 127.

Whitaker, D. R. (1952). An effect of proteins and proteoses on the cellulase of Myrothecium verrucaria. Science, 116, 90.

(Received 1 September 1955) 